\title{
Tradução em contexto de crise: uma abordagem narrativa
}

\author{
Junia Claudia Santana de Mattos Zaidan* \\ Ana Carolina Justiniano ${ }^{\star *}$ \\ Patrick Rezende ${ }^{\star * *}$
}

\begin{abstract}
Resumo
Exploramos neste trabalho os modos como se dá a disputa entre narrativas concorrentes através de atos de tradução que inscrevem o conflito resultante tanto das lacunas interculturais entre participantes, quanto - e sobretudo em face da economia política da violência étnico-racial, de gênero e sexual, na sociedade de classes. Tomada como efeito material e simbólico dos regimes metadiscursivos estruturantes das narrativas sociais, a violência é focalizada enquanto resultado de processos de tradução que se apresentam como espelhamento da realidade, solicitando, assim, tanto sua problematização quanto a visibilização das disputas pela narração. Compõem o corpus analisado as traduções intra e interlinguais feitas por coletivos voluntários como prática contradiscursiva às narrativas veiculadas pelo oligopólio midiático brasileiro ao longo do processo de consolidação do golpe de 2016 no Brasil, entre março e agosto de 2016. A análise indica como limites da tradução ativista sua natureza reativa e também a dependência excessiva das redes sociais, o que refreia sua penetração, trânsito e sedimentação na esfera pública. Recorrendo a novas e criativas formas de afirmação política frente às narrativas dominantes, a tradução ainda assim se fortalece como campo de resistência e luta social.

Palavras-chave: Golpe de 2016. Tradução e narrativa. Tradução e ativismo. Tradução e transformação social. Tradução voluntária. Tradução e mídia.
\end{abstract}

* Universidade Federal do Espírito Santo, doutora em linguística, professora adjunta de língua inglesa. Orcid https://orcid.org/0000-0003-1857-3432.

* Secretaria de Estado da Educação do Espírito Santo. Mestre em Linguística Aplicada, professora de língua inglesa. Orcid https://orcid.org/0000-00023880-3779.

* Secretaria de Estado da Educação do Espírito Santo, doutor em Estudos da Linguagem, professor de língua inglesa. Orcid https://orcid.org/0000-00016680-9353.

Cadernos CESPUC de Pesquisa. Série Ensaios. n.38, $1^{\circ}$ Sem./2021, p. 201-219.

e-ISSN: 2358-3231 (OJS). Recebido em: 19/07/2021. Aceito em: 14/09/2021. 


\title{
Translation in critical times: a narrative approach
}

\author{
Júnia Cláudia Santana de Mattos Zaidan \\ Ana Carolina Justiniano \\ Patrick Rezende
}

\begin{abstract}
This paper explores how competing narratives dispute the public sphere by means of acts of translation, inscribing the conflict resulting both from intercultural gaps among participants, and from the political economy of ethnical-racial, gender and sexual violence in capitalist societies. Taken as the material and symbolic effect of metadiscursive regimes that structure social narratives, violence is focused upon as the result of translatorial processes that present themselves as the mirror of reality, which requires problematization as well as the visibilization of the narratives in dispute. The corpus is made of intra and interlingual translations carried out by volunteer collectives opposing Brazilian media mainstream outlets throughout the process of the 2016 coup d'Etat in Brazil. The analysis points to the limitations of activist translation given its responsive nature as well the over-reliance on social media, which prevents it from penetrating and consolidating in the public sphere. Still, translation as resistance and social struggle has strengthened by resorting to new creative forms of political affirmation in face of dominant narratives.

Keywords: 2016 Coup d'État. Translation and narrative. Translation and activism. Translation and social change. Volunteer translation. Translation and the media.
\end{abstract}




\section{Introdução}

Eu falo, falo - diz Marco -, mas quem me ouve retém somente as palavras que deseja. Uma é a descrição do mundo à qual você empresta a sua bondosa atenção, outra é a que correrá os campanários de descarregadores e gondoleiros às margens do canal diante da minha casa no dia do meu retorno, outra ainda a que poderia ditar em idade avançada se fosse aprisionado por piratas genoveses e colocado aos ferros na mesma cela de um escriba de romances de aventuras. Quem comanda a narração não é a voz: é o ouvido (CALVINO, ,1990 p. 57).

Depreendemos da afirmação aqui epigrafada do explorador Marco Polo, tomado por Calvino em sua obra ficcional Cidades Invisíveis, que a história não é independente dos sistemas de representação e que é sempre possível, sobre o mundo, uma narrativa diversa daquela que enunciamos ou daquelas às quais somos expostos. As narrativas que dão forma material (textual) aos eventos são múltiplas e, a partir das relações que estabelecem no espaço em que disputam os ouvidos, passam a ordenar a vida social.

'Narrativa' é um daqueles conceitos nas humanidades que podem ter diferentes definições não só de um autor e/ou campo disciplinar para outro, mas também, no âmbito de uma mesma disciplina.

Aqui, 'narrativa' será pensada a partir da apropriação que Baker (2006; 2016) faz do modelo de Somers e Gibson (1994) para conceituar tradução como um processo inexoravelmente "inescapável através do qual experimentamos o mundo" " (BAKER, 2006, p. 9, tradução nossa). Esta noção não deixa de se relacionar, em algum nível, com os conceitos de 'discurso', em Foucault (2004) e 'mitos', em Barthes (1982). Exploramos, assim, como se dá a disputa entre narrativas concorrentes através de atos de tradução que inscrevem o conflito resultante das lacunas interculturais entre participantes e da economia política da violência colonial, étnicoracial, de gênero, sexual, sempre pensada como produto da sociedade de classes. Tomada como efeito material e simbólico dos regimes metadiscursivos estruturantes das narrativas sociais, a violência é focalizada enquanto resultado de processos de tradução que se apresentam como

1 “(...) the principal and inescapable mode by which we experience the world" (BAKER, 2006, p. 9). 
espelhamento da realidade, solicitando, assim, tanto sua problematização quanto a visibilização das disputas pela narração. Reconheça-se que esta visada sobre os processos de tradução tornou-se não só uma possibilidade, mas sobretudo uma agenda de pesquisa na área, principalmente a partir das contribuições de Lawrence Venuti (cf. VENUTI, 1995; 1998) em cuja obra a tradução é teorizada como prática de resistência que não permite o apagamento de sua natureza ética, ideológica e que, portanto sublinha sua potência de agenciamento. De modo ilustrativo, comporão esta breve discussão traduções de coletivos de ativistas políticos ao longo do processo de consolidação do Golpe de 2016 no Brasil.

Cumpre observar que a tradução recobrirá tanto a noção clássica de retextualização entre dois sistemas de signo distintos (entre o espanhol e o português / o português e o inglês, por exemplo), ou seja, o artefato textual envolvendo os elementos formais (ligados à forma linguística) e as estratégias de tradução, que têm vasta taxonomização. Aprofundaremos a reflexão sobre o conceito de tradução a fim de incluir atos, tais como a seleção de tópicos, a decisão sobre quais línguas e de quais fontes são traduzidas, a projeção da perspectiva / da visão de mundo de certos grupos, a decisão de traduzir e a decisão em si de não traduzir, a reescrita de enunciados como contra-narrativa, o recurso a certos suportes, o uso de imagens, a associação de imagem e texto, a justaposição de textos, a justaposição de imagens, todos como prática tradutória, que se realiza no que estamos chamando de narrativa.

\section{Tradução como narrativa e a violência produzida na/pela linguagem}

A impossibilidade de os sujeitos situarem-se fora da ordem narrativa impõe a qualquer análise dos textos e discursos que estruturam a vida social o reconhecimento de que estamos sempre posicionados, assumindo algum dos múltiplos lados que constituem a ordem social. Baker afirma:

Tudo que conhecemos é o resultado de inúmeras histórias que se imbricam e nas quais os atores socias estão situados.(...) Jerome Bruner argumenta ainda 204 Junia Claudia Santana de Mattos Zaidan, Ana Carolina Justiniano \& Patrick Rezende 
que as narrativas não só representam, mas constituem a realidade (1991, p. 5). Uma narrativa, em termos de comunicação social, não é necessariamente traçável em um texto específico, mas dá sustentação a uma gama de textos e discursos podendo nem ser necessariamente total ou explicitamente articulada em nenhum deles (BAKER, 2016, p.464, tradução nossa). ${ }^{2}$

Segundo o modelo de Somers \& Gibson (1994), são quatro os tipos de narrativa: (1) narrativas ontológicas: nossas histórias pessoais, aquelas que, embora sejam, por natureza, produzidas socialmente, apontam para o indivíduo e seu contexto pessoal (por ex. "eu sou de esquerda porque não me conformo com o mundo"); (2) narrativas públicas: circulam institucionalmente, socialmente, no âmbito da religião, família, educação, política, mídia (por ex., "a educação pública é de má qualidade", "políticos são corruptos", "temos uma democracia racial no Brasil”; (3) narrativas conceituais: são as explicações e representações que construímos, enquanto analistas, pesquisadores e que penetram a esfera das narrativas públicas (por ex. a suposta irredutibilidade das diferenças culturais como causa e justificativa - de conflitos entre civilizações) e (4) metanarrativas: são o grande teatro histórico em que somos atores sociais, constituídos por narrativas do que seja, por exemplo, progresso, decadência, segurança, terrorismo. As metanarrativas são temporal e fisicamente amplas, produzindo uma sensação de inevitabilidade. Neste trabalho, focalizaremos as narrativas públicas, que embora se entrecruzem com as demais categorias, são particularmente produtivas para compreendermos os desdobramentos dos eventos políticos por incorporarem uma suposta "voz pública".

$\mathrm{Na}$ arena discursiva em que estamos posicionados, portanto, não é a veracidade dos fatos que está em disputa, mas a narrativa em si, posto que a linguagem e a textualização, em uma abordagem narrativa, não são tomadas como processos transparentes, mas opacos. Isso impossibilita tanto a suposta detecção dos "fatos" quanto a constituição de pontos neutros a partir dos quais alguém estaria em condições de indicar a verdade do mundo. Como afirmou Julio Cortázar em seu conhecido ensaio sobre a condição do romance, "o que chamamos história é a presa mais certa e completa

\footnotetext{
2 "Everything we know is the result of numerous crosscutting story-lines in which social actors locate themselves "(1994, p. 41). Jerome Bruner further argues that narrative is "a form not only of representing but of constituting reality (1991, p.5) It follows that a given narrative, in the social and communication theory sense is not necessarily traceable to one specific stretch of text but is more likely to underpin a whole range of texts and discourses without necessarily being fully or explicitly articulated in any one of them" (BAKER, 2016 p. 464).
} 
da linguagem" (CORTÁZAR, 2011, p.62), enunciado que permite dizer, a respeito do assunto em pauta, que, como prática discursiva, a tradução não representa uma realidade exatamente como esta supostamente é, mas a apresenta de uma certa forma; que não reproduz supostos conteúdos e sentidos de um texto de partida, mas os produz.

O que cimenta uma narrativa no terreno social não é o fato de ser enunciada, até porque isso não ocorrerá explicitamente, na forma dos estratos que exemplificamos ao apresentar as categorias de Somers e Gibson. As narrativas públicas são suturadas em nosso imaginário coletivo pela indiretividade de que se vale o discurso, por meio da repetição garantida por mecanismos institucionais, discursivos ou não (por ex. livros didáticos, regras formuladas para a convivência em um determinado espaço, a disseminação de informação pelas mídias comerciais, e outros componentes da cultura de comunicação social etc.). Tal dinâmica produz, como corolário, assimetrias e tensionamentos ininterruptos, que geram incontáveis formas de violência, uma vez que não é toda narrativa que consegue emergir, adquirir visibilidade, valor e permanência na esfera pública. Depende desta estabilidade garantida pela suposta univocidade e homogeneização das narrativas uma ecologia na qual os sujeitos "narrados" acabam por introjetar a 'sombra', como diz Freire (1987, p.18), dos narradores, em uma relação dialética que perpetua a opressão.

Para a análise das incontáveis formas de violência estruturantes da vida social, interessa-nos o modo como as narrativas públicas que circulam, via tradução, obliteram assimetrias de diversas naturezas entre os grupos sociais, assim naturalizando e impondo os valores e práticas das hegemonias constituídas, o que examinamos brevemente na seção a seguir.

\section{Tradução como contra-narrativa em situações de exceção}

Talvez soe como um truísmo dizer que, na maioria absoluta dos países latino-americanos, a mídia de massa sempre teve papel fundamental em impedir a transformação social (cf. AVITZEER \& COSTA, 2004; NONATO, 2014). A mídia comercial latinoamericana sempre se dedicou, de igual modo, a garantir que interesses políticos corporativos internacionais 
de países hegemônicos sempre prevalecessem em relação às aspirações e necessidades de nações como Venezuela, Argentina, Chile, Colômbia, Honduras, Brasil etc. Na verdade, as tentativas de construção de uma cultura de comunicação social democrática na America Latina precisam ser analisadas considerando o contexto mais amplo de luta das antigas colônias em resistência ao processo europeu de acumulação primitiva de capitais, que teve o protagonismo dos países ibéricos. Hoje, este papel é desempenhado pelos Estados Unidos, cuja influência e poder (muitas vezes na forma de intervenção militar) capilarizam-se por aqui das mais diversificadas formas (cf. SORJ, 2011; ZAIDAN et al, 2017).

No Brasil, a despeito dos princípios constitucionais que preveem a regulamentação da mídia, ${ }^{3}$ por exemplo, com a proibição de monopólios e da propriedade cruzada dos meios - conglomerados midiáticos de direita dominam $70 \%$ dos canais de notícia. Trata-se de apenas cinco famílias (Marinho, Civita, Frias, Saad e Macedo, proprietárias, respectivamente, dos grupos Globo, Abril, Folha, Bandeirantes e Record) que têm a voz e a vez na esfera pública nacional, bem como penetração na esfera política (muitos parlamentares são donos de emissoras de rádio e televisão, prática inconstitucional). O controle social exercido pela mídia vale-se justamente do apagamento e silenciamento de vozes dissidentes em relação aos interesses das elites, disseminando perspectivas, opiniões, visões de mundo, isto é, suas narrativas, sem qualquer lastro do conjunto da sociedade brasileira (cf. GUIMARÃES; AMORIM, 2013), este, plural, diverso e rico. Decorre desse processo a manutenção dos privilégios das elites e o aprofundamento da assombrosa desigualdade social que nos constituiu historicamente, através de uma agenda econômica ultraliberal, gerando todas as possíveis e brutais formas de violência que testemunhamos diariamente.

A resistência às narrativas dos oligopólios midiáticos brasileiros é aqui examinada brevemente, tomando-se as traduções realizadas por diversos coletivos de tradução voluntária estudados no período de março a setembro de 2016, quando se consolidou o golpe jurídico-parlamentar-

\footnotetext{
3 O Capítulo V da Constituição Federal versa exclusivamente sobre a comunicação social, estabelecendo os princípios que deveriam ser posteriormente regulamentados pela Conferência Nacional de Comunicação (Confecom), a ser convocada pelo Executivo, após a promulgação da Carta Magna, em 1988. Somente em 2009 houve a convocação da $1^{\text {a }}$ Confecom pelo então presidente Luís Inácio Lula da Silva, que foi boicotada por todos os donos das empresas ligadas à mídia comercial, sob a alegação de que se tratava de tentativa de censura, narrativa amplamente disseminada na esfera pública pelos próprios donos do oligopólio midiático brasileiro. A realização da Confecom estabeleceria balizas para as práticas de comunicação social no país, até hoje eivadas de inconstitucionalidade, como o monopólio, a não observância do princípio da complementaridade entre os sistemas público, privado e estatal, por exemplo.
} 
midiático no Brasil (GONÇALVES, 2018). A Brigada Herzog ${ }^{4}$, A Televisão do $M u n d o^{5}$ e a Caneta Desmanipuladora ${ }^{6}$ são exemplos mais estruturados desses coletivos, que contam com equipes de profissionais e já têm expressiva notoriedade nas redes sociais. Contudo, dois outros coletivos de organização bastante fluida e horizontalizada, anônimos e com número flutuante de participantes, também foram objeto desta análise, a qual se tornou possível devido à participação de uma das autoras deste artigo nas atividades de tradução.

A marcada polarização da opinião pública gerou uma clivagem que exibia, de um lado, os que entendiam ser golpe a tentativa de destituir a então Presidenta Dilma Rousseff e, do outro, os que criam ser um procedimento dentro da legalidade institucional. O impeachment tinha o apoio da grande mídia, de amplos setores da classe média em geral, das elites políticas, do mundo corporativo, com expressão dos setores do agronegócio, do mercado financeiro e de agentes internacionais ligados às questões de matriz energética (petróleo e gás). Já a alegação de que se tratava de um golpe era feita por grande parte da classe trabalhadora, seções sindicais, movimentos sociais e estudantis, ativistas pelos direitos humanos, parte expressiva da mídia internacional, bem como artistas e intelectuais, de forma geral. Os coletivos estudados situavam-se politicamente no pólo que acusava o processo de impeachment de ser um golpe ao Estado Democrático de Direito.

Agenciando tradutores, revisores, jornalistas entre outros profissinais, os coletivos produziram no referido período contranarrativas na forma do que foi postulado por Jakobson (1995) como tradução interlingual (legendagem de vídeos do português para diversas línguas e de diversas línguas para o português: artigos jornalísticos, moções, notas de repúdio, abaixo-assinados, cartas abertas de diversos movimentos sociais, associações e representações de inúmeros segmentos da sociedade civil) e tradução intralingual (retextualização de manchetes com intervenção no discurso veiculado pela mídia de massa, artigos e matérias antagônicos, frequentemente em reação aos textos da mídia comercial, entre outros).

\footnotetext{
4 Segundo a descrição que apresenta em sua página na internet, "A Brigada Herzog é um organização supra-partidária, antifascista, antigolpista, com objetivo de oferecer ao mundo, em todos os idiomas, uma narrativa mais democrática e plural do que vem acontecendo no Brasil." (Disponível em: https://www.ocafezinho.com/2016/03/26/brigada-herzog-ja-nasce-grande-mais-de-300-militantes/ )

5 De acordo com sua página no Facebook, dedica-se a apresentar "O Brasil visto de fora no noticiário internacional. Reportagens e vídeos legendados em português que mostram o Brasil que a mídia nacional esconde." (Disponível em: https://www.facebook.com/pg/televisaodomundo/about/?ref=page_ internal)

6 Dedicada a reescrever manchetes de jornais e de portais da grande mídia, a Caneta Desmanipuladora apresenta-se "como o maior observatório de grande mídia com alcance de massa da internet brasileira."
}

208 Junia Claudia Santana de Mattos Zaidan, Ana Carolina Justiniano \& Patrick Rezende 
As narrativas públicas (BAKER, 2016) de relevo para o pólo próimpeachment são apresentadas no Quadro 1. Saturamos essas narrativas a partir das análises feitas pelo site Manchetômetro, que utiliza a Metodologia de Análise de Valências (MAV), interrogando a posição assumida por cada texto em relação aos assuntos ou personagens em pauta, a qual é codificada como positiva, negativa, neutra ou ambivalente. Embora haja controvérsia sobre a eficácia desta metodologia (cf. debate entre MIGUEL, 2015 e FERES JÚNIOR, 2016), sobretudo por presumir a possibilidade de neutralidade jornalística e também por alegadamente reduzir as práticas de comunicação a tratamentos estatísticos, julgamos ser um ponto de partida produtivo quando conjugado com o modelo narrativo de Baker (2016) em tradução, que reitera a posicionalidade inexorável dos sujeitos e o imbricamento entre as diferentes narrativas da taxonomia proposta. Consideraram-se, de março a agosto de 2016, as capas das revistas Isto É e Veja, bem como as manchetes principais e os editoriais dos jornais impressos Folha de São Paulo, Estado de São Paulo e O Globo, as quais alinham-se com o noticiário televisivo dos mesmos grupos (Jornal Nacional, Jornal da Record, Jornal da Band etc), não considerados neste estudo.

\section{Quadro 1 - Narrativas públicas disseminadas pela grande imprensa brasileira (março a agosto de 2016)}

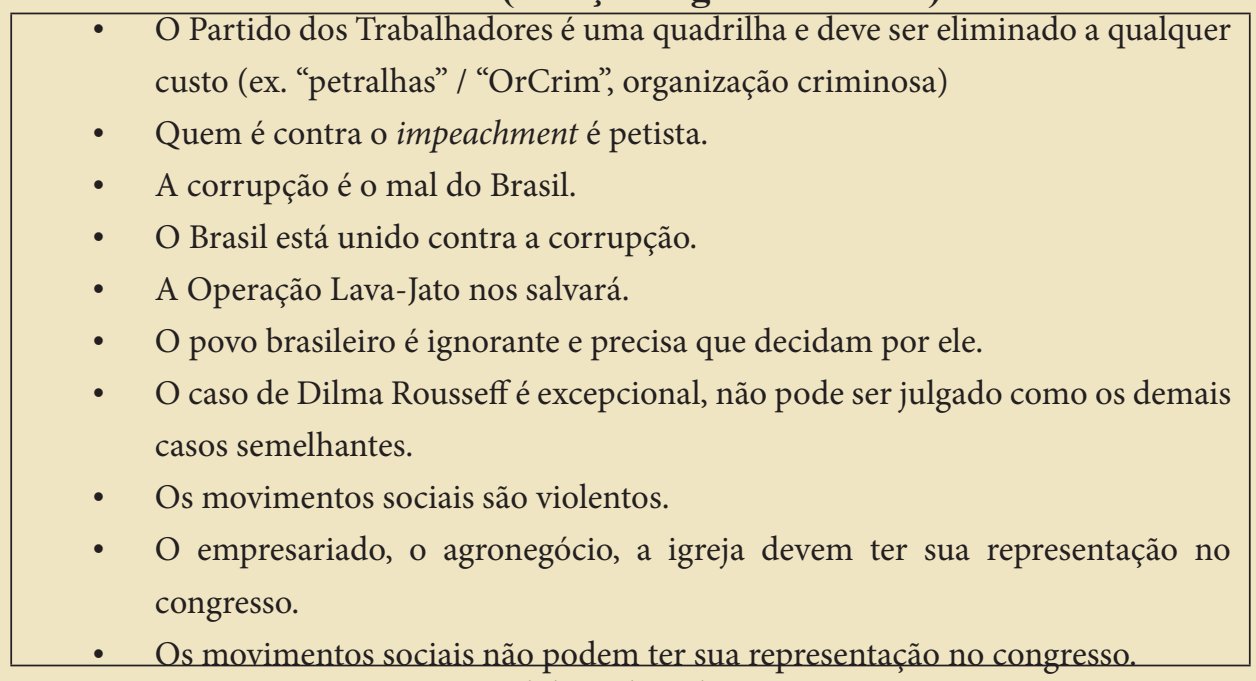

Fonte: elaborado pelos autores 
As contra-narrativas se construíram, como mencionamos, através de várias práticas discursivas. Por falta de espaço, exemplificamos apenas as amostragens de tradução interlingual da Brigada Herzog (Quadro 2) e algumas ocorrências de retextualização (tradução intralingual), feitas pelo coletivo Caneta Desmanipuladora, de duas manchetes da grande imprensa (Captura de Tela 1 e 2).

\section{Quadro 2 - Brigada Herzog: legendagem de vídeos do inglês para o português. Reportagem da Al Jazeera, março de 2016}

Fragmento 1: Nos últimos dois anos, as revistas Veja e Época foram criticadas pela cobertura mal fundamentada desta história. Alex Quadros, um jornalista que trabalha em São Paulo, escreveu um artigo longo acusando as revistas de fazerem alegações vagas sem apresentar qualquer prova documental.

Fragmento 2: Uma coisa de que as pessoas se tornaram mais conscientes é de que há setores da mídia que estão tentando tirar vantagem política dessa questão e assim, forçar um impeachment (...) através do Judiciário.

Fragmento 3: É um jornalismo de baixa qualidade, pois não há nenhuma prova, só insinuações (...) É uma guerra de informação.

\section{Fonte: elaborado pelos autores}

Dentre os numerosos vídeos legendados pelos coletivos, selecionamos fragmentos deste em que há um investimento na narrativa sobre a tendenciosidade da mídia brasileira. No período compreendido pelo estudo, o ativismo político via tradução frequentemente se dedicou a promover o debate sobre a própria mídia, além de cobrir outros temas. Venício Lima, pesquisador da comunicação social brasileira, tem incansavelmente afirmado que o Brasil é um dos poucos países em que "a mídia não debate a mídia", o que reforça a relevância dos movimentos contranarrativos, uma vez que pautam temas silenciados, invisibilizados ou lhes conferem enquadramentos diversos do olhar tradicional que nossa mídia comercial lhes dirige.

A partir do exemplo acima, destacamos também a prática da tradução interlingual como mecanismo para tentar validar nacionalmente a narrativa pública da comunidade internacional. Reportagens sobre o golpe feitas por canais como a Al Jazeera, o DemocracyNow e até mesmo 
canais tradicionais de notícia, como a $\mathrm{CNN}$, entre outros, foram traduzidas e disseminadas pelas redes sociais, como uma reiteração da narrativa dos movimentos sociais, intelectuais, acadêmicos, mas a partir de um lugar de fala distinto - o estrangeiro. Porque temos a sensação de que a validação externa teria peso para reverter o golpe pode ser respondido por nossa história colonial. Seria mais fácil convencer os brasileiros de que estávamos sob a ameaça de um golpe se quem dissesse isso não fossem os brasileiros, mas a comunidade internacional? Esse trânsito dos coletivos entre textos oriundos de diversos países e do Brasil também incluiu a tradução principalmente, entre o português, o inglês, o espanhol, alemão, francês, italiano, de manifestações públicas (notas de repúdio, moções, cartas abertas, notas em desagravo, abaixo-assinados), emitidas por instituições brasileiras e/ou estrangeiras posicionando-se contra o golpe. Ainda que esses atos de tradução (ou sua repercussão) precisem ser pensados em sua relação com nossa condição pós-colonial, como dissemos, necessariamente indicam que a ruptura institucional produzida pelo golpe em um contexto de aguda crise de nosso sistema de representação política, teve como desdobramento certo fortalecimento das diversas instâncias de representação da sociedade civil, a qual, por mais que pareça antagônico, aparenta tomar como inevitável a ação política institucional nas lutas por representatividade e visibilidade.

Imagem 1: tradução intralingual, 8 de junho de 2016

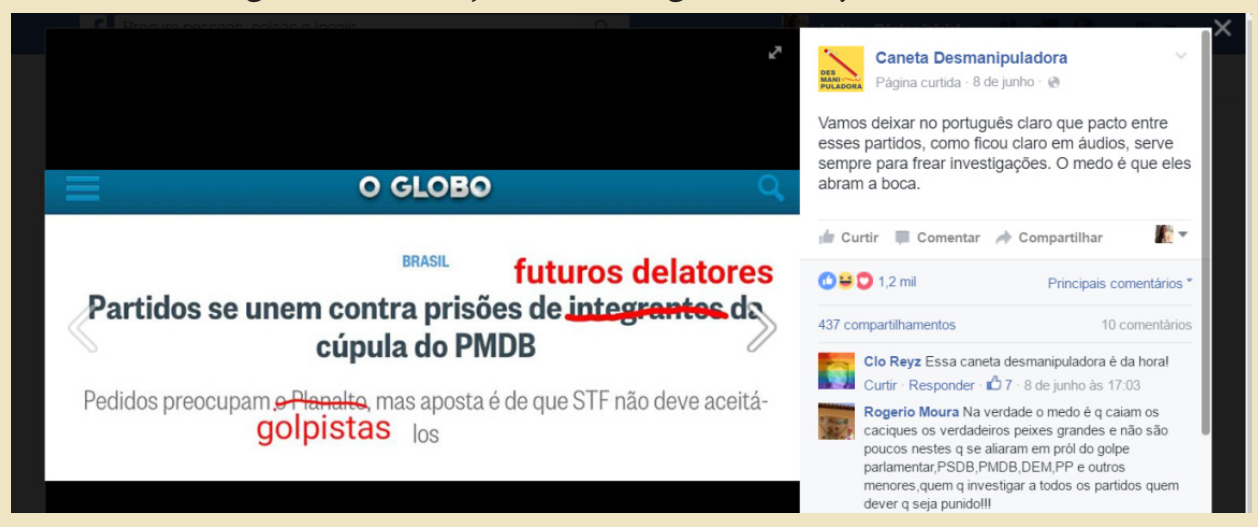

Fonte: Caneta Desmanipuladora, 2016 


\title{
(1)
} POLÍTICA

OPERAÇÃO LAVA JATO

\section{Áudio revelapolilíticos discutindo saidade Dilma e criticando Judiciário}

\author{
Gravaçōes inéditas mostram conversas entre \\ Machado, Sarney e Jucá. Sérgio Machado \\ gravou conversas e fechou acordo de delação \\ premiada.
}

26/05/2016 21h05 - Atualizado em 27/05/2016 07h48

Do G1, com informaçōes do JN

Fonte:Caneta Desmanipuladora, 2016

Nessas capturas de tela, a tradução intralingual ou retextualização cumpre o papel de tornar salientes tanto o notório enviesamento da mídia comercial, quanto a disputa pela narrativa. Note-se que, sem a reescritura em vermelho do texto, a narrativa inicial poderá parecer acima de qualquer suspeita em relação à "neutralidade" jornalística. A intervenção no texto dilata o discurso, forçando-o a explicitar a diferença constitutiva entre perspectivas e posicionalidades. Sobre "O Planalto", expressão que remeteria à autoridade legítima, efetua-se um deslize pelo uso da palavra "golpistas", muito contestada pelos favoráveis ao impeachment, naturalmente, por ser altamente disfórica. A narrativa da mídia é posta em xeque quando o termo "integrantes", neutro, é traduzido como "futuros delatores", expressão de cunho pejorativo, que visa à exposição dos partidos que assaltaram o poder em 2016. A reformulação da aparentemente inofensiva expressão "saída de Dilma" para "golpe de estado em Dilma” oferece outra perspectiva a respeito dos áudios vazados sobre a grande farsa montada para justificar o golpe. A natureza ardilosa da conspiração contra Dilma se salienta pela tradução intralingual. 
As principais contranarrativas públicas que emergiram dos diversos atos de tradução compreendidos na totalidade do material coletado - ainda que aprenas parcialmente apresentado aqui - podem ser enunciadas como (1) É golpe; (2) Rousseff não infringiu a lei de responsabilidade; (3) O golpe é misógino; (4) A mídia brasileira é parcial; (5) Os movimentos sociais apóiam Rousseff e (6) Os manifestantes pró-golpe pertencem à elite socioeconômica.

Sintetizamos no Quadro 3 uma sistematização dos recursos discursivos utilizados pelos pólos antagônicos na construção cotidiana das narrativas que circularam - e ainda circulam - a respeito da situação política Brasileira.

Quadro 3: Narrativas como construção discursiva

\begin{tabular}{|l|l|}
\hline \multicolumn{1}{|c|}{ Mídia Empresarial } & \multicolumn{1}{|c|}{ Coletivos de Tradutores Voluntários } \\
\hline $\begin{array}{l}\text { Atenuadores, eufemismo e omissão como } \\
\text { mecanismos discursivos para legitimar o } \\
\text { golpe }\end{array}$ & $\begin{array}{l}\text { Uso afirmativo de termos como "golpe" e } \\
\text { "conspiração" }\end{array}$ \\
\hline $\begin{array}{l}\text { Promoção de manifestações pró-golpe } \\
\text { e apagamento ou cobertura mínima das } \\
\text { manifestaçães anti-golpe }\end{array}$ & $\begin{array}{l}\text { transmissão ao vivo pela internet (redes } \\
\text { sociais) das manifestações e atos anti- } \\
\text { golpe }\end{array}$ \\
\hline $\begin{array}{l}\text { Representação homogeneizada de grupos } \\
\text { anti-golpe (todos são "Petistas") }\end{array}$ & $\begin{array}{l}\text { Representação de diversos grupos no } \\
\text { movimento anti-golpe, e do dissenso } \\
\text { entre alguns }\end{array}$ \\
\hline $\begin{array}{l}\text { Quase totalidade dos editoriais pró-golpe } \\
\text { (valência negativa ou neutra) }\end{array}$ & $\begin{array}{l}\text { Análises incluem visões críticas ao } \\
\text { Partido dos Trabalhadores, à esquerda, } \\
\text { mas contrárias ao impeachment }\end{array}$ \\
\hline $\begin{array}{l}\text { Locus enunciativo garantido a alguns } \\
\text { juristas favoráveis ao golpe e tempo/ } \\
\text { espaço de fala maior para parlamentares } \\
\text { pró-golpe }\end{array}$ & $\begin{array}{l}\text { Locus enunciativo garantido a intelecuais, } \\
\text { acadêmicos, artistas, estudantes e a } \\
\text { comunidade internacional progressista, } \\
\text { anti-golpe }\end{array}$ \\
\hline Criminalização dos movimentos sociais & $\begin{array}{l}\text { Espaço para a expressão e/ou adesão aos } \\
\text { movimentos sociais }\end{array}$ \\
\hline $\begin{array}{l}\text { Divulgação de matérias de canais } \\
\text { internacionais que adotaram narrativa de } \\
\text { "impeachment". }\end{array}$ & $\begin{array}{l}\text { Divulgação de matérias de canais } \\
\text { internacionais que adotaram narrativa de } \\
\text { golpe }\end{array}$ \\
\hline Combate à corrupção como bandeira. & $\begin{array}{l}\text { Divulgação de análises que incluem, mas } \\
\text { não se restringem à corrupção }\end{array}$ \\
\hline $\begin{array}{l}\text { "Framing" positivo das políticas de } \\
\text { austeridade e cortes em políticas ligadas } \\
\text { ao bem estar sosial }\end{array}$ & $\begin{array}{l}\text { Apoio à luta contra a perda de direitos } \\
\text { ligados ao trabalho, previdência e } \\
\text { educação }\end{array}$ \\
\hline
\end{tabular}

Fonte: elaborado pelos autores

Tradução em contexto de crise: uma abordagem narrativa 


\section{Considerações finais}

Serão cinco, dez, cem narrativas distintas a respeito da consolidação do Golpe de 2016 no Brasil. Diante do cenário desolador do ponto de vista social, político e econômico que vivemos hoje, o reconhecimento de que a orquestração de forças para aligeirar a implantação da agenda ultraliberal no Brasil dependia da derrubada do governo de Rousseff. Registre-se a campanha que a Federação das Indústrias do Estado de São Paulo (Fiesp) fez em prol do impeachment de Rousseff, sob o argumento de que não "pagaria o pato" pelo que considerava erros da administração de Rousseff. Quem está pagando o pato, no entanto, tem sido a classe trabalhadora e os grupos sociais mais vulneráveis, como se pode depreender da breve exposição da análise realizada, através da qual, uma vez mais, - se constatou o fracasso histórico de nossas práticas de comunicação social em compor a esfera pública a partir das narrativas democraticamente distribuídas. Isso se deve sobretudo à massificação mantida pelo oligopólio midiático de alcance incomparável ao dos coletivos de resistência cujas contranarrativas dependem principalmente das redes sociais.

No que concerne à disputa narrativa, um dos limites da tradução neste trabalho foi seu pendor para a reatividade, traço também detectado por Tymoczko (2010) em seus estudos sobre tradução e ativismo. Contudo, a polarização ideológica que refreou eventuais posicionamentos autônomos e propositivos por parte dos coletivos não impediu que ademais se confirmasse o papel da tradução como prática de contestação e de luta social, ainda que a batalha que os coletivos - e expressiva parcela da sociedade civil organizada e dos movimentos sociais - travaram contra o Golpe de 2016 tenha sido perdida, com a sucessão de eventos após a destituição de Dilma Rousseff (GONÇALVES, 2018; ZAIDAN et. al., 2019), quais sejam, a implementação de uma agenda ultraliberal, com o consequente desmonte da estrutura de bem estar social (trabalhista, previdenciária, privatização irrestrita, austeridade fiscal etc.); a instalação de um ambiente policialesco e persecutório do dissenso, sobretudo do dissenso manifestado pela classe intelectual, que inclui de modo especial os professores (ex. Projeto Escola Sem Partido, projetos de lei denuncistas contra a autonomia para ensinar etc.); a prisão política, em abril de 2018, de Luís Inácio Lula da

214 Junia Claudia Santana de Mattos Zaidan, Ana Carolina Justiniano \& Patrick Rezende 
Silva, que figurava então nas pesquisas como candidato favorito à sucessão presidencial e, ao fim e ao cabo, a legitimação do golpe através da eleição de Jair Messias Bolsonaro, em um processo eleitoral eivado de irregularidades, crime eleitoral inequívoco, leniência do Tribunal Superior Eleitoral, recusa do então candidato a debater seu plano de governo com a sociedade e a disseminação de fake news como estratégia narrativa indefensável para os demais candidatos.

A crise a que se refere o título deste artigo tanto aponta para um estado estruturante - e, portanto, constante - do modo de produção em que vivemos (afinal, o capitalismo é a crise), quanto os acontecimentos que puseram a lume a fragilidade da democracia nos marcos do Estado burguês. Ao ponto de chegarmos ao ano de 2021 com a cerca de 590 mil mortos pela política de gestão da pandemia. As narrativas aqui analisadas sedimentaram de diversas formas o contexto violento, desigual e obscurantista do momento presente brasileiro.

\section{Referências}

AVITZEER, L.; COSTA, S. Teoria crítica, democracia e esfera pública: concepções e usos na América Latina. In: DADOS - Revista de Ciências Sociais. Rio de janeiro, v. 47, n. 4, p. 703-728, 2004.

BAKER, Mona. Translation and conflict: a narrative account. Londres/ Nova Iorque: Routledge, 2006.

BAKER, Mona. Translating dissent: Voices from and with the Egyptian Revolution. Londres/Nova Iorque: Roudledge, 2016.

BARTHES, R. Mitologias. Tradução de Rita Buongermino e Pedro de Souza. São Paulo: Difel, 1982.

CALVINO, I. As cidades invisíveis. Tradução de Diogo Mainardi. São Paulo: Companhia das Letras, 1990.

CANETA DESMANIPULADORA. Disponível em: https://www.facebook. com/canetadesmanipuladora/. Acesso em: 25 nov. de 2018. 
CORTÁZAR, J. Octaedro: contos. Tradução de Gloria Rodriguez. Bestbolso. Rio de Janeiro, 2011.

FERES JÚNIO, J. Em defesa das valências: uma réplica. Revista Brasileira de Ciência Política. Brasília, n. 19, p. 277-298, jan./abr. 2016.

FOUCAULT, M. A ordem do discurso. Tradução de Laura Fraga de Almeida Sampaio. 10. ed. São Paulo: Edições Loyola, 2004.

FREIRE, P. A pedagogia do oprimido. Rio de Janeiro: Paz e Terra, 1987.

GONÇALVES, M. (org.). Enciclopédia do golpe. Vol. 2 - O Papel da Mídia. Bauru: Canal, 2018.

GUIMARÃES, J.; AMORIM, A. P. A corrupção da opinião pública. São Paulo: Boitempo, 2013.

JAKOBSON, R. Linguística e comunicação. Tradução de Izidoro Blikstein e José Pauo Paes. São Paulo: Cultrix, 1995.

MIGUEL, L. F. Quanto vale uma valência? Revista Brasileira de Ciência Política. Brasília, n. 17, p. 165-178, mai./ago. 2015.

NONATO, C. Venício Lima: em defesa da democratização dos meios de comunicação. Comunicação \& Educação. São Paulo, v. 19, n. 1, p. 8392, 2014. Disponível em: <http://www.revistas.usp.br/comueduc/article/ view/78571>. Acesso em: 25 jul. 2018.

SOMERS, M. R.; GIBSON, G. D. Reclaiming the Epistemological "Other": narrative and the social constitution of identity. In: CALLOUN, Craig (org.). Social theory and the politics of identity. Oxford/Cambridge: Blackwell, 1994. p. 37-99.

SORJ, B. (org.). Meios de comunicação e democracia: além do Estado e do mercado. Rio de Janeiro: Centro Edelstein de Pesquisas Sociais. 2011.

TYMOCZKO, Maria (org.). Translation, resistance, activism. University of Massachussetts Press. Amherst e Boston, 2010.

VENUTI, L. The translator's invisibility: a history of translation. London: Routledge, 1995. 
VENUTI, L. The scandals of translation: towards an ethics of difference. London: Routledge, 1998.

GONÇALVES, Mírian (org). Enciclopédia do Golpe, Vol 2: O Papel da Mídia. Canal Editora. Bauru, 2018.

ZAIDAN, Junia, et al. (org.). Cultura e imperialismo americano. 2. ed. Vitória: Leitura Fina, 2017.

ZAIDAN, Junia; MARSIGLIA, Ana Carolina Galvão e SALGUEIRO, Wilberth (org.). Foi Golpe! O Brasil de 2016 em análise. Campinas: Pontes Editores, 2019. 
219 Junia Claudia Santana de Mattos Zaidan, Ana Carolina Justiniano \& Patrick Rezende 